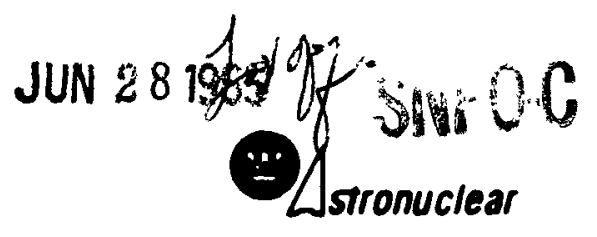

WANL-TME-1176

May 19, 1965

Submitted By:

Westinghouse Electric Corporation

Astronuclear Laboratory

Pittsburgh 36, Pennsylvania

\title{
INTERIM REPORT ON THERMOCOUPLE SHEATH DEVELOPMENT
}

(Instrumentation Development Task T-3)

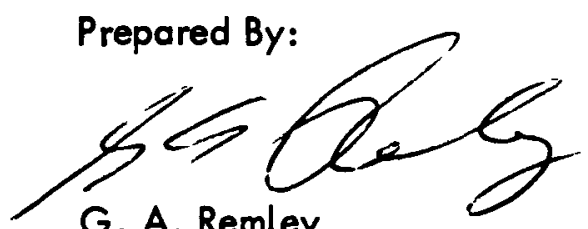

G. A. Remley Instrumentation Development Instrumentation and Control

Approved By:

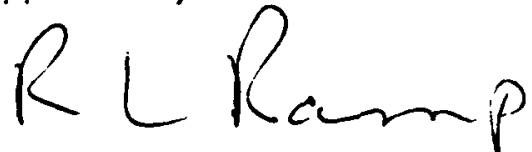

R. L. Ramp, Manager Instrumentation Development Instrumentation and Control

\section{INFORMATION CATEGORY}

UNCLASSIFIED

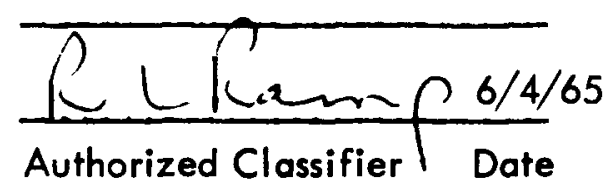




\section{DISCLAIMER}

This report was prepared as an account of work sponsored by an agency of the United States Government. Neither the United States Government nor any agency Thereof, nor any of their employees, makes any warranty, express or implied, or assumes any legal liability or responsibility for the accuracy, completeness, or usefulness of any information, apparatus, product, or process disclosed, or represents that its use would not infringe privately owned rights. Reference herein to any specific commercial product, process, or service by trade name, trademark, manufacturer, or otherwise does not necessarily constitute or imply its endorsement, recommendation, or favoring by the United States Government or any agency thereof. The views and opinions of authors expressed herein do not necessarily state or reflect those of the United States Government or any agency thereof. 


\section{DISCLAIMER}

Portions of this document may be illegible in electronic image products. Images are produced from the best available original document. 


\section{J.1. Dooline}

Nenva Subeontivet Monager

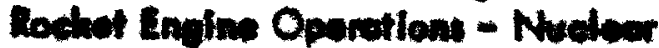

Deppomanat 7140

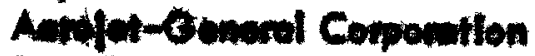

Pes Othes $\operatorname{cox} 1947$

Survinimonto, Colliomio

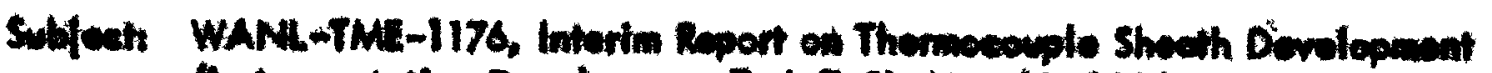

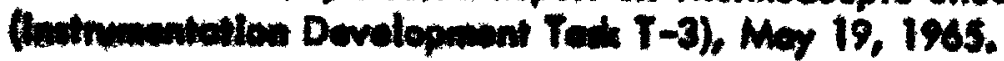

Dear Mt. Doolinge

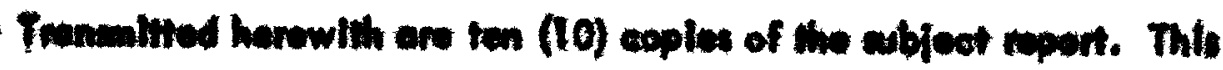
mport b tremualthed for your Information.

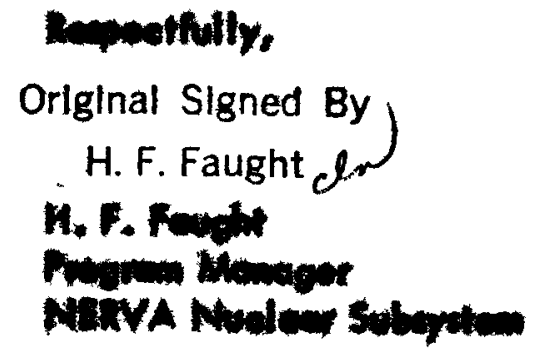

Demently.

Original Signed By H. F. Faught $\ell$ -

H. F. Fough

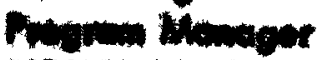

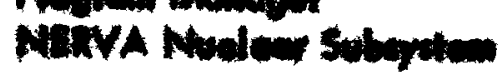

\section{Evatemen -10}

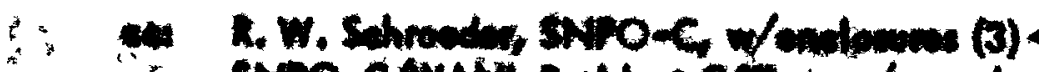

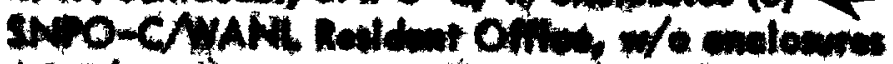

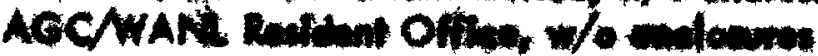

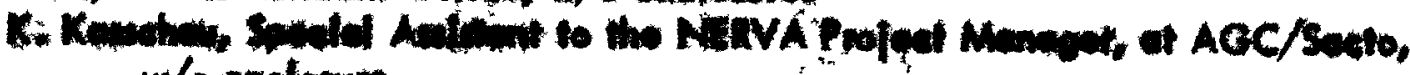
we andowit.

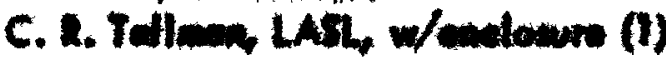

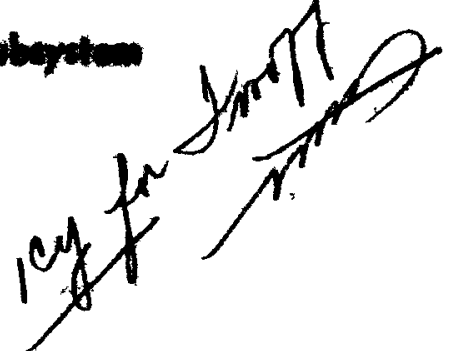

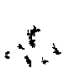




\title{
INTERIM REPORT ON THERMOCOUPLE SHEATH DEVELOPMENT
}

\author{
(Instrumentation Development Task T-3)
}

\section{Introduction}

The successful solution to the NRX Reactor high temperature core element thermocouple problem hinges to a large degree on the ability to evolve a sheath that will protect the thermoelements and insulation against degradation by the reactor environment which causes failure by carbiding and/or hydriding.

Summary of Progress

To solve this problem, Instrumentation Development Task T-3 has been set-up to be a concentrated program to obtain the quickest and best solution. This program involves working with supplier sources to obtain specimens of candidate materials, testing these materials in simulated reactor environments in prototype thermocouple configurations and analyzing the results to determine the ability of the material tested to protect the thermocouple system.

As a result of tests performed to date we have qualified molybdenum as a sheath material for use in core element thermocouples at temperature levels up to $3660^{\circ} \mathrm{R}$. We have disqualified tantalum due to its failure by hydriding and resultant effects on the core element in which it is installed. We have determined that vapor deposited tungsten tubing is too brittle for serious consideration for reactor installation. The full temperature capability of molybdenum will be explored to determine its maximum temperature qualification level. Evaluation samples of wrought tungsten-rhenium alloys, vapor deposited tungsten-henium alloys, and tungsten coated versions of the latter two !:ems are now on order. An order for extruded tungsten tubing is presently being negotiated. In addition metal oxide protective coatings over refractory metals are being considered and types of oxide to be tested together with problems of procurement and application are presently being explored.

Thermocouple sheath development, until approximately October 1964, had been more or less based on "fixes" of existing sheaths with sheath selections being based primarily on materials that were known to and used by the thermocouple manufacturers. This approach led to the present configuration for station 45 core element thermocouples of molybdenum tubing protecting the thermocouple insulation with tantalum tubing over the molybdenum to prevent carbiding of the molybdenum and tungsten coating over the tantalum to prevent hydriding of the tantalum. Thermocouples of this design have not yet proven to be satisfactory insofar as sheath survival is concerned. To date we have not obtained tungsten coating over the tantalum that has been sufficiently impervious to hydrogen to properly protect it. In addition we have evidence that molybdenum is incompatible with $\mathrm{BeO}$ insulation at station 45 temperatures and is marginally compatible at station 32 temperatures. 
As an initial step towards solving the problem of developing a sheath system that would survive the reactor environment and protect the thermocouple, a series of materials compatibility tests was run by the WANL Materials Department. These tests were designed to determine the effects of $\mathrm{BeO}$ insulation on refractory metals at high temperatures. They showed that molybdenum in contact with $\mathrm{BeO}$ forms molybdenum beryllide. At $3730^{\circ} \mathrm{R}$ this effect is only slightly apparent. At $4720^{\circ} \mathrm{R}$ the molybdenum deteriorates badly. At $4900^{\circ} \mathrm{R}$ it disappears completely, leaving only reaction products. More testing is necessary to determine how much above $3730^{\circ} \mathrm{R}$ rapid disintegration begins. Tantalum, tungsten and tungsten rhenium alloys did not show serious degradation when tested in a similar manner.

\section{Development Program}

Using this Materials Department input as a partial basis for our program, we are proceeding as follows to develop reliable thermocouple sheaths:

1. Molybdenum (Carbon Eutectic Mel ting Point $4480^{\circ} \mathrm{R}$ )

1.1 Bare Molybdenum

1.1.1 On the basis of full size qualification tests on thermocouple designs using bare molybdenum sheaths we have qualified this material for the reactor environment to temperatures up to $3660^{\circ} \mathrm{R}$. This qualification is reported in IC-letter 4101 dated February 23, 1965.

1.1.2 Bare molybdenum has the potential of qualification to higher temperature levels than $3660^{\circ} \mathrm{R}$. However, we have not yet run the necessary tests to upgrade the qualification. A series of qualification tests on station 26 thermocouples is imminent. Bare molybdenum test specimens will be placed in this test to determine if there are higher temperature levels to which bare molybdenum can be requalified.

\subsection{Coated Molybdenum}

Vapor deposited tungsten coating over molybdenum has the potential of further elevating the usable temperature range. The tungsten coating, which is more resistant to carbiding than is molybdenum, can act as a barrier to carbiding of the molybdenum in the reactor environment. If this barrier can be made sufficiently effective, molybdenum has the potential of qualification up to the temperature at which it reacts with the beryllium oxide insulators (Approximately $4500^{\circ} \mathrm{R}$ ). Our present design of station 26 and 32 thermocouples has a vapor deposited tungsten coated molybdenum sheath with .085" O.D. and .010" wall. Since a series of qualification tests is in progress for both thermocouple designs, we will evaluate these test results for temperature level qual ification of this sheath. 
Also, to more fully evaluate the contribution that the tungsten coating makes as a carbiding barrier we will place bare molybdenum test specimens in these tests. Thus, in addition to evaluating the effectiveness of tungsten coating, we should also learn more about the necessity for tungsten coating over molybdenum. Our present thermocouple design requires complete assembly of the molybdenum sheathed probe before vapor deposition as we now require tungsten coating over the welded molybdenum plug that is both the tube closure and the thermocouple wire junctioning plug. This necessitates handling of the entire thermocouple in the coating operation with resultant increased possibilities of damage in handling. We should therefore be certain as to the contribution of tungsten coating in this system.

2. Tantalum (Carbon Eutectic Mel ting Point $5720^{\circ} \mathrm{R}$ )(Hydriding Temperature Range $1700-2000^{\circ} \mathrm{R}$ )

\subsection{Bare Tantalum}

Tantalum tubing is disqualified by IC -4304 dated April 7, 1965 as a thermocouple sheath material. This disqual ification is the result of our inability to protectively overcoat the tantalum against catastrophic failure by hydriding with resultant damage to the fuel element in which it is installed.

Tantalum has many desirable characteristics that make it a good candidate for thermocouple sheath material. It has a melting point of $5885^{\circ} R$ and a carbon eutectic point of $4720^{\circ}$. It is ductile and workable and can be machined to shape. It could be a solution to many of our sheath problems if it did not have the characteristic of rapidly hydriding at $1700-2000^{\circ} \mathrm{R}$ with resultant quick deterioration and swell ing of the reaction product. However, until we prevent hydriding by some process with almost perfect reliability, tantalum will not be a satisfactory material for fuel element thermocouples.

\subsection{Tungsten Coated Tantalum}

At present this material is disqualified for fuel element thermocouple sheaths. Attempts to provide a hydrogen impervious coating by vapor deposition of tungsten have not proven successful. Tungsten coating as applied by Wheaton Industries did not record a single success in the NRX-A2 test run, in the qualification test of NRX-A3 station 45 thermocouples which resulted in thermocouple design 978D251HO1 being omitted from the reactor or in NRX-A4 qualification testing of station 45 thermocouples of design 978D272H01. Tungsten coating as applied by San Fernando Laboratories had one success in the NRX-A4 station 45 qual ification tests. However, we also recorded two failures of their tungsten coating in this test series.

No further test work is planned on tungsten coated tantalum. If highly reliable tungsten coatings become available at some future date, the situation should be reevaluated at that time. 


\subsection{Coatings Other Than Tungsten Over Tantalum}

It may be possible to use tantalum tubes coated with refractory oxides to act as both a gas barrier and a carbiding barrier. A coating of hafnium oxide, for example, if it could be applied in a sufficiently continuous film to be gas tight should be considered. Present development plans of General Electric - NMPO are in the direction of oxide coating over refractory metal tubes. However, tantalum is not presently being considered as the hydriding problem could be a deterrent to an early solution of a workable station 45 thermocouple, which is the objective of this development program. However, any metal oxide coatings evolved in this program should be tried on tantalum at a later date due to the relative low cost and ready availability of tantalum as compared to the other refractory metals.

Properly protected tantalum, in spite of the problem of hydriding, still has the long range possibility of being the lowest cost fuel element thermocouple sheath material.

\section{Tungsten (Carbon Eutectic Melting Point $-5500^{\circ} \mathrm{R}$ )}

Tungsten tubing would probably solve our fuel element thermocouple sheath problems if we could get it in a usable form. In the past, tungsten was not available in tubular form in sufficiently long lengths. However, recent developments have now made it available in vapor deposited and wrought forms.

\subsection{Vapor Deposited Tungsten Tubing}

Vapor deposition is an expedient that has been used to obtain a tubular shape of tungsten. It is fundamentally a plating process which reduces a halide salt (usually tungsten hexafluoride) to the constituent metal element in a controlled atmosphere and pressure environment. In making tungsten tubing by this process, tungsten is deposited either onto the surface of a stretched wire mandrel or onto the inside surface of a tubular mandrel. The mandrel is then etched away, leaving a tungsten tube. The surface of the tungsten deposited against the mandrel will have the same surface as the mandrel. The other surface will be a relatively rough mat finish. The mat finish surface is relatively uncontrolled insofar as dimensional tolerances are concerned and adequate allowances must be made in using it.

Tungsten in wrought form is a brittle material that requires care in handling to minimize breakage. In the vapor deposited form, it has a glass-like fragility that makes handling it in long, small diameter fubular length an extremely delicate operation. Handling breakage is high and our experience to date indicates that the assembly problems are almost insurmountable. 
In addition to being fragile, we have not yet been able to procure vapor deposited tungsten tubing that is leak tight. Also, the vapor deposition process normally yields a layer of metal with a columnar structure that is a poor barrier to carbiding. Since the sheath must be a carbiding barrier to protect both the thermocouple wires and insulators, vapor deposited tungsten may not be adequate for the application. Additional samples of vapor deposited tungsten tubing have been ondered from San Femando Laboratories. While the order is on a "best efforts" basis, this tubing is being produced to be leak tight and to have the columnar structure sufficiently eradicated to provide a carbiding barrier. This tubing will be checked for helium leak tightness, will be examined metallurgically and will be used as a sheath material on prototypes to determine its ability to protect the thermocouple components.

\subsection{Extruded Tungsten Tubing}

Extruded tungsten tubing, which to our knowledge is the only wrought form of tungsten tubing being produced, has been available for about a year. There is only one source, Metallonics, Inc., in Boston, Massachusetts. Only a small amount has been produced (180 feet up to February 1965). The price structure is very indefinite and to date it has been difficult to negotiate an order. Prices that start out in verbal preliminaries at $\$ 15.00$ an inch escalate to $\$ 25.00$ or $\$ 30.00$ an inch when quotations are written down. The Instrumentation Application Section experienced difficulty on price negotiation for extruded tungsten sheaths for an A4 "fix" to the point that they did not place the order. An attempt to place a development order is encountering similar difficulties. However, despite negotiation difficulties, we should place an order for this tubing as we must have an evaluation as to its potential.

The extruded tungsten tubing will be a brittle material and will require care in handling. However, it will not be as fragile as vapor deposition tungsten. It will carbide but the rate may be sufficiently slow that we can get the necessary survival time for a reactor run. The lamellar structure of the wrought metal will el iminate the direct path found in the columnar structure of vapor deposited metal and should result in a tortuous path for carbon transmission. This could prove to be an effective carbon barrier.

Extruded tungsten tubing may also exhibit better gas tightness than vapor deposited tubing. Our experience to date indicates that the vapor deposited tubing is relatively porous and exhibits leaks too large to calibrate on our helium leak tester. The supplier of the extruded material will not make any quarantees as to leak rate at present. However, the basic structure of the metal should result in low or negligible leak rates. 
The procurement of extruded tungsten tubing to dimensional configuration and tolerances and to gas tightness specifications is proving to be a tedious job. This is primarily due to the infancy of the art of producing this product. However, since it seems to be the best potential solution now known we should pursue this development.

It is our present program to find a basis and price structure on which to place a development order. The finished tubing will be fabricated into prototype thermocouple samples for evaluation.

\section{Tungsten Rhenium Alloys (Carbon Eutectic Melting Point $4900^{\circ} \mathrm{R}$ )}

We have no real experience with the use of tungsten rhenium alloys as thermocouple sheath materials. They have been available from Hoskins Manufacturing Company as wrought tubes prior to the start of our high temperature thermocouple development program. While reasons for not evaluating are not well defined it is likely that the high cost has been the largest deterrent. A secondary factor has been difficulty in procuring desired sizes of tubing. However, had we made proper efforts we could have procured evaluation quantities of this material in tubular form.

The two alloys available are tungsten - 5 per cent thenium and tungsten - 26 per cent rhenium, with the latter more available from Hoskins Manufacturing Company stock.

\subsection{Bare Tungsten-Rhenium Alloy Tubing}

\subsubsection{Wrought Tubing}

Wrought tungsten-rhenium tubing with no protective coating is not in the present evaluation program. Due to its extremely high cost we will delay placing any orders for this material until we have more experience with it in tungsten coated and vapor deposited forms.

\subsubsection{Vapor Deposited Tubing}

Vapor deposited tungsten-rhenium alloy tubing has been made only on an experimental basis by San Fernando Laboratories. However, they are now accepting orders for this material and we have entered requisitions for an evaluation sample of tungsten - 26 per cent rhenium tubes. We have been verbally assured that this material will have superior ductility to tubes made by a wrought process and that the density will be over 98 per cent of theoretical. However, this order is on a "best efforts" basis so we cannot be certain as to the characteristics of the material we will receive. The justifications for evaluating vapor deposited tubing rather than wrought tubing is that we can obtain it quicker, we get better dimensional control and the cost is approximately 75 per cent that of wrought tubes. 


\subsection{Coated Tungsten-Rhenium Alloy Tubing}

The carbon eutectic melting temperature of the tungsten thenium alloy system is not sufficiently high that the metal will be usable over our complete reactor environment temperature range. However, since the melting point of tungsten-26 rhenium is $6040^{\circ} \mathrm{R}$, the metal could be successfully used as a sheath material if we could prevent or delay carbiding. Therefore coated tubing should be evaluated.

\subsubsection{Tungsten Coated Wrought Tungsten 26 Rhenium}

The Instrumentation Application Section has ordered 23 wrought tungsten - 26 rhenium alloy tubes from Hoskins Manufacturing Company as a possible A4 station 45 thermocouple "fix." These tubes will be vapor deposited with tungsten by San Fernando Labs to provide what we hope will be an effective carbiding barrier. Three tubes will be on a "best efforts" basis to be made quickly and fabricated into thermocouples for qualification testing in the hydrogen corrosion fumace. The fabrication of the remaining 20 will be held pending results of furnace testing on the first three tubes. The tubes on these three qualification test thermocouples will serve as the Development Section evaluation samples.

\subsubsection{Tungsten Coated Vapor Deposited Tungsten - 26 Rhenium Tubing}

Vapor deposition usually results in a relatively poor interface bond between the coated and the coating metal. Also, differential coefficients of thermal expansion tend to deteriorate the bond when the metals are heated. To el iminate this area of differential expansion, San Fernando Labs has proposed the manufacture of vapor deposited tungsten - 26 rhenium alloy tubes with the rhenium gradually phased out so that the outer .002 inch layer of the tube wall is tungsten. This technique should result in a tightly adherent tungsten coating with a gradual transition zone to minimize differential thermal expansion. In addition, the more ductile tungsten - 26 rhenium alloy inner area should result in a tube that is more handleable than vapor deposited tungsten.

We hove placed a development order with San Fernando for five of these tubes for evaluation.

\section{Other Alloys}

The alloy combinations considered to this point are those that offer the quickest solution to our high temperature thermocouple sheath problems regardless of cost due to either material cost or to high breakage resulting from material fragility. In addition, we are presently willing to settle for relatively short sheath life (one hour). However, 
metals technology is progressing and new alloys are becoming available, either commercially or as laboratory products. To pursue all systems at present would result in much confusion and little progress. However, this alloy development should be continually surveyed and noted for future reference and possible evaluation. Present alloys in this category are a series of tungsten rhenium molybdenum combinations being produced at General Electric NMPO and molybdenum rhenium alloys being produced by Chase Brass and Copper Company.

\section{Other Protective Coatings}

To this point in our program, the only protective coatings evaluated have been vapor deposited tungsten over tantalum and molybdenum. The possibility of using metal oxide coatings was suggested by General Electric NMPO and will be partially evaluated in the development program we are having them conduct for us. They propose a protective layer of hafnium oxide over a refractory metal tube to act as a carbiding barrier and thus inhibit deterioration. We should be able to evaluate this approach as part of our test program of the prototype thermocouples that the development program requires them to delivery.

Another coating technique that will be explored will be refractory metal tubes layered with crystal grown magnesium oxide. We recently placed a crystal of magnesium oxide in a core element qualification test of a station 45 thermocouple in contact with the graphite and located at the hottest point. Post-test examination indicated no deterioration of the crystal. We are now negotiating with Semi-Elements, Inc., the supplier of the crystals, to determine if we can get crystals grown directly and continuously on the tubes. Small pieces of tantalum and molybdenum tubing hove been sent to this company for experimental work.

\section{Existing Design "Fixes"}

The work of the Instrumentation Application Section in attempting to obtain a "fix" that will qualify the station 45 thermocouples in time for NRX-A4 assembly is being closely followed. As indicated in section 4.2.1 they have a program that parlays San Femando Labs and Hoskins Manufacturing Company to obtain a tungsten coated tungsten - 26 rhenium tube "fix" that will be evaluated. They have also obtained three tantalum tubes that have been coated with .007 inch of vapor deposited tungsten by San Fernando Labs. The objective of this procurement was to determine if a heavier tungsten coating than previously used would serve to provide the necessarily high reliability barrier to hydrogen and thus prevent hydriding of the tantalum tube. These tubes will be built into prototype thermocouples and tested.

\section{Supplier Development}

In addition to finding alloys that have the necessary environmental resistance characteristics the problem is compounded by the necessity for finding sources of supply with the equipment and technology to manufacture the materials into long length small 
diameter tubes. It is not possible to work with suppliers as is customary for the more commercial materials, by conveying your needs to a potential source and having that source expend time and materials on the problem's solution to obtain a new market. The bosic materials are so expensive and the potential market so indefinite that practically all development and evaluation samples must be purchased, usually at a very high price that insures the supplier against any losses due to possible production difficulties. In addition, most orders are accepted only on a "best efforts" basis.

To interest a supplier in furnishing tubing for evaluation, the quantity must usually be sufficient to incur an order cost of approximately $\$ 3000.00$. This results in very expensive sample procurement. However, if the problems are to be solved, this type of expenditure is necessary. Another aspect of sample procurement that makes it expensive is the necessity of developing the suppliers' capability to produce lengths of tubing sufficiently long for our use. We have followed several promising leads on potential refractory metal tubing sources only to find that the vendors maximum production capability was six inches or twelve inches or some other unusable length. Even in the case of San Fernando Labs and Metallonics, Inc. it has been necessary to enter requisitions for tubes to required lengths on a "best efforts" basis so the vendor could establish his own capability to supply the necessary lengths. To fully establish vendor potential to supply our needs, it will continue to be necessary to follow the expensive pattem of ordering in quantities of approximately five tubes to full probe length on a "best efforts" basis. 